\title{
TRANSTORNO DE DÉFICIT DE ATENÇÃO E HIPERATIVIDADE: O QUE OS PROFESSORES DE CIÊNCIAS DE CONFRESA SABEM SOBRE O ASSUNTO?
}

\author{
Mara Maria Dutra ${ }^{1}$ \\ Dalila Helena Silva²
}

\section{RESUMO}

O Transtorno de Déficit de Atenção e hiperatividade (TDAH) é um transtorno neurobiológico, de causas genéticas, que surge na infância e que desencadeia sérias dificuldades para o processo de aprendizagem. Frente ao exposto objetivou-se por meio dessa pesquisa verificar se os professores de ciências que atuam nos anos finais do Ensino Fundamental, da cidade de Confresa (MT) conhecem o Transtorno de Déficit de Atenção e Hiperatividade e como realizam sua prática pedagógica com esses estudantes. Trata-se de uma pesquisa exploratória e descritiva, ocorrida no primeiro semestre de 2017 , de natureza básica com abordagem qualitativa. Os dados da pesquisa foram coletados por meio de formulário entregue a oito professores de ciências, que atuam nos $8^{\circ}$ e $9^{\circ}$ anos do Ensino Fundamental das redes estaduais, municipal e particulares da cidade de Confresa (MT). Os resultados confirmam que os professores de ciências investigados demonstraram possuir conhecimento insipiente acerca do TDAH. Conhecimento que não é suficiente para terem certeza que estão lidando com um estudante com TDAH ou para questionarem a

\footnotetext{
1 Mestra em Ciências Ambientais pela Universidade do Estado de Mato Grosso (UNEMAT), Professora Pedagoga do Departamento de Ensino do Instituto Federal de Educação, Ciência e Tecnologia de Mato Grosso, Campus Barra do Garças. Pesquisadora do grupo de pesquisa em Ensino de Ciências e Matemática no Baixo Araguaia (GPEnCiMa). ORCID: https://orcid.org/0000-0003-3944-9107. Email: mara.dutra@bag.ifmt.edu.br

2 Especialista em Ensino de Ciências pelo Instituto Federal de Educação, Ciência e Tecnologia de Mato Grosso (IFMT), Campus Confresa/MT. Email: dalilahistoria@gmail.com
} 
respeito da saúde mental de estudantes e assim contribuir para o processo de tratamento e aprendizagem do mesmo. A percepção dos sintomas de TDAH por estes profissionais é limitada pela falta de conhecimento que vai além do senso comum. Assim, como proposta para amenizar esta problemática pretende-se em trabalhos futuros propiciar a capacitação sobre o TDAH como instrumento para que esses professores possam desenvolver uma conduta adequada objetivando o sucesso escolar desses estudantes.

Palavras-chave: TDAH. Professores de ciências. Inclusão.

\section{ATTENTION DEFICIT HYPERACTIVITY DISORDER: WHAT DO CONFRESA'S SCIENCE TEACHERS KNOW ABOUT IT?}

\section{ABSTRACT}

Attention Deficit Hyperactivity Disorder (ADHD) is a genetically caused neurobiological disorder that arises in childhood and triggers serious difficulties in the learning process. Therefore, this study aims to verify whether science teachers who work in the late years of Elementary Education in the city of Confresa (MT) are aware of Attention Deficit Hyperactivity Disorder and how they perform their pedagogical practice with those students. This research is exploratory and descriptive, of a basic nature, from a qualitative approach, and was carried out in the first half of 2017. The research data were collected through a form provided to eight science teachers who work in the 8th and 9th years of state, municipal and private Elementary Education schools in the city of Confresa (MT). The results confirm that the investigated science teachers demonstrated incipient knowledge of ADHD. Such knowledge is not sufficient to ensure that they are dealing with an ADHD student or to question about the mental health of the student and thus be able to contribute towards the process of treatment and to learn from it. The perception of ADHD symptoms by these professionals is limited by the lack of knowledge that lies 
beyond common sense. Thus, as a proposal to alleviate this problem, the intention is that future efforts be made to provide training on ADHD as a tool for teachers to develop an adequate attitude aimed at the success of these students.

Keywords: ADHD. Science teachers. Inclusion.

\section{TRASTORNO POR DÉFICIT DE ATENCIÓN E HIPERACTIVIDAD: ¿QUÉ SABEN LOS PROFESORES DE CIENCIAS DE CONFRESA AL RESPECTO?}

\section{RESUMEN}

El Trastorno por Déficit de Atención e Hiperactividad (TDAH) es un trastorno neurobiológico, de causas genéticas, que surge en la infancia y que desencadena serias dificultades para el proceso de aprendizaje. En vista de lo anterior, el objetivo de esta investigación fue verificar si los docentes de Ciencias que laboran en los últimos años de la escuela primaria en la ciudad de Confresa (MT) conocen el Trastorno por Déficit de Atención con Hiperactividad y cómo realizan su práctica pedagógica con estos estudiantes. Se trata de una investigación exploratoria y descriptiva, realizada en el primer semestre de 2017, de carácter básico con enfoque cualitativo. Los datos de la investigación fueran recopilados mediante un formulario entregado a ocho profesores de Ciencias, que laboran en el octavo y noveno año de la educación primaria en escuelas estatales, municipales y privadas de la ciudad de Confresa (MT). Los resultados confirman que los profesores de Ciencias en estudio demostraron tener un conocimiento insipiente sobre el TDAH. Conocimientos que no son suficientes para asegurarlos de que se trata de un alumno con TDAH o para cuestionar la salud mental de los alumnos y así contribuir con el proceso de tratamiento y aprendizaje del mismo. La percepción de los síntomas del TDAH por parte de estos profesionales es limitado por el desconocimiento que va más allá 
del sentido común. Así, como propuesta para paliar este problema se pretende en futuros trabajos proporcionar la formación en TDAH como instrumento para que estos docentes puedan desarrollar una conducta adecuada con miras al éxito escolar de estos estudiantes.

Palabras clave: TDAH. Profesores de Ciencias. Inclusión.

\section{INTRODUÇÃO}

No mundo contemporâneo a educação formal adquiriu grande importância sociocultural. No entanto, movimentos em prol da inclusão de estudantes com necessidades especiais em classes comuns de ensino, vêm provocando debates no meio escolar, principalmente a partir da última década do século XX.

Considerando esse quadro, percebe-se a necessidade de mudanças nas políticas públicas e nas práticas docentes, referente a estudantes com necessidades educativas especiais (NEE), dentre esses, estão os que apresentam disfunção de aprendizagem, como os casos de Transtorno do Déficit de Atenção e Hiperatividade (TDAH) (SILVA; DUTRA, 2016).

A questão problematizadora dessa pesquisa surgiu de indagações pessoais, da vontade de contribuir com a formação de professores que desconhecem o transtorno e por consequência, quem sabe, auxiliar no caminho para algum diagnóstico. A história que está por traz da vontade de conhecer o que os professores de ciências sabem sobre o transtorno, começa na formação inicial desta autora, licenciada em História, que desconhecia os transtornos mentais e suas implicações na aprendizagem de estudantes. Tal desconhecimento implicou significativamente em minha vida pessoal, quando o "problema" passou a estar dentro de casa, sou mãe de um filho com transtorno e tive dificuldades para identificar do que se tratava, por que meu filho tinha tanta dificuldade em aprender? Nunca fui orientada pela escola, que sempre reclamava de seu comportamento, a buscar ajuda de um profissional de saúde. Me deparei com o desconhecimento de professores e de profissionais de saúde, quando inicialmente busquei ajuda. 
A escolha dos profissionais que trabalham com ciências derivou da necessidade de enquadramento deste artigo nesta temática, exigida pelo curso de pós-graduação em Ensino de Ciências do IFMT campus Confresa.

Para dar início às elucidações a respeito do TDAH é importante dizer que surge na infância, é considerado um transtorno neurobiológico e suas causas são genéticas. Apresenta como principal característica a falta de atenção, a hiperatividade e a impulsividade, isso acontece porque em regiões sinápticas do lobo frontal do cérebro ocorre uma baixa concentração de dopamina e/ou noradrenalina, que provoca sérias dificuldades durante o processo de aprendizagem (ASSOCIAÇÃO BRASILEIRA DE TRANSTORNO DE DÉFICIT DE ATENÇÃO E HIPERATIVIDADE, 2016c).

De acordo com a Associação Brasileira de Déficit de Atenção de Hiperatividade (ASSOCIAÇÃO BRASILEIRA DE TRANSTORNO DE DÉFICIT DE ATENÇÃO E HIPERATIVIDADE, 2016c), dificuldades de competência linguística, na capacidade expressiva e/ou controle motor fino ou grosso e nas habilidades organizacionais são alguns dos padrões de comportamento apresentados em pessoas com TDAH. Para Fernandes e Viana (2009), outro desafio referente à inclusão de estudantes com TDAH em classes comuns de ensino, diz respeito ao modo como a escola e seus educadores percebem esse estudante. Muitas vezes, o fato de percebê-lo como diferente prejudica o processo de inclusão.

Esse estudo se justifica por atender ao universo de inquietações de uma professora, que em sua formação acadêmica, não teve conhecimentos a respeito das patologias psiquiátricas e suas influências na aprendizagem dos estudantes, e que teve o desafio pessoal de ser mãe de uma criança com o transtorno. Desde muito cedo a inteligência e oralidade excepcionais do meu filho intrigava a todos, no entanto, em contraposição, ele apresentava dificuldade de concentração, de atenção e de motivação para com os estudos.

Este trabalho justifica-se também, por se tratar de uma das patologias psiquiátricas mais frequentes em estudantes. Estima-se que a cada 100 estudantes de três a sete, apresentem o transtorno. Assim surge o desejo de indagar: Estão os professores preparados profissionalmente, com conhecimentos necessários para minimizar a 
situação do TDAH? De acordo com Beltrame, Silva e Saviski (2007), as instituições de ensino superior ainda apresentam lacunas nos cursos de formação de professores e uma dessas lacunas está relacionada à inclusão de pessoas com NEE, na qual se insere a questão do atendimento as pessoas com TDAH.

Nesse sentido, entende-se que os professores deveriam estar preparados para realizar uma prática pedagógica com estratégias que atendam a grande diversidade dos estudantes. E como dito anteriormente, também são necessárias alterações nas políticas públicas educacionais, visando oportunizar as escolas com condições (recursos humanos, materiais, infraestrutura, entre outros) de atendimento para que o processo de inclusão se efetive.

Diante do exposto, a presente pesquisa teve como objetivo verificar se os professores de ciências que atuam nos anos finais do Ensino Fundamental, na cidade de Confresa (MT), conhecem o TDAH e como realizam a prática pedagógica com esses estudantes. Para tanto, foram investigados oito professores que atuam na disciplina de ciências, nas escolas urbanas do município de Confresa (MT).

A fim de proporcionar um melhor entendimento, o estudo está estruturado da seguinte forma: primeiramente uma seção com o tema Transtorno de Déficit de Atenção e Hiperatividade e sua relação com a inclusão, que apresenta um paralelo da atual situação de estudantes com TDAH e o que é preciso para que a inclusão acorra; na sequência é apresentado o texto que aborda o TDAH e suas implicações no ensino de ciências tratando dos objetivos vislumbrados pelos profissionais desta área e as dificuldades geradas pelo transtorno. Depois dessa revisão bibliográfica, os materiais e métodos descrevem os percursos metodológicos da pesquisa, e na sequência são apresentados os resultados e discussões, e por fim, as considerações finais da pesquisa.

\section{TRANSTORNO DE DÉFICIT DE ATENÇÃO E HIPERATIVIDADE E SUA RELAÇÃO COM A INCLUSÃO}

O TDAH é um transtorno que tem como data oficial de sua primeira descrição o ano de 1902, George Still, pediatra inglês, 
apresentou casos de crianças com hiperatividade e outras alterações de comportamento. Desde então, várias pesquisas foram realizadas a fim de descobrir as áreas afetadas do cérebro, os padrões de comportamento para diagnóstico e o que ocorre com os neurotransmissores (ASSOCIAÇÃO BRASILEIRA DE TRANSTORNO DE DÉFICIT DE ATENÇÃO E HIPERATIVIDADE, 2016d).

Segundo Silva (2010), o TDAH se caracteriza por três sintomas básicos: desatenção, impulsividade e hiperatividade física e mental. $\mathrm{O}$ autor afirma que esse transtorno:

Costuma se manifestar ainda na infância e em cerca de $70 \%$ dos casos o transtorno continua na vida adulta. Ele acomete ambos os sexos, independentemente do grau de escolaridade, situação socioeconômica ou nível cultural, o que pode resultar em sérios prejuízos na qualidade de vida das pessoas que o têm, caso não sejam diagnosticadas e orientadas precocemente (SILVA, 2010, p. 7).

Trata-se de um dos diagnósticos de distúrbios de comportamento mais comum para crianças em idade escolar. É considerado um transtorno específico de aprendizagem, responsável por casos de repetência e evasão escolar que chega a atingir, segundo estimativas médicas, de 3 a $7 \%$ das pessoas em idade escolar (SILVA, 2010).

Essa disfunção age de forma importante sob as várias habilidades cognitivas necessárias para o aprendizado (ABDA, 2016d). Segundo o Manual Diagnostic and Statistical Manual of Mental Disorders ${ }^{3}$ IV (DSM IV, 2000 apud SILVA, 2010, p. 164), cada indivíduo combina os sintomas de forma diferenciada. Portanto, o TDAH pode ser dividido em três tipos: 1) com predomínio de sintomas de desatenção; 2) com predomínio de sintomas de hiperatividade/impulsividade e 3) com os três sintomas combinados.

Deste modo, há dificuldades para se realizar um diagnóstico precoce, geralmente são encaminhas para tratamento casos que apresentam prejuízos nas áreas social, familiar e escolar. Outro fator

\footnotetext{
${ }^{3}$ Manual Diagnóstico e Estatístico de Transtornos Mentais IV.
} 
a se considerar são as dificuldades no aprendizado, que somadas aos preconceitos existentes no Brasil em relação aos transtornos e patologias mentais e a estrutura de nossa educação, dificultam a inclusão desses estudantes.

Esse fato corrobora a ideia de que quando se aborda o tema TDAH, nos deparamos com conceitos abrangentes como o de inclusão. Segundo Alves (2009, p. 15), incluir é:

\begin{abstract}
Abranger, compreender, envolver, implicar, acrescentar e somar. Portanto, é necessário que se compreenda que qualquer educando pode ser incluído, pois devemos agregá-lo, somá-lo a qualquer outro indivíduo para que ambos cresçam.
\end{abstract}

Ainda segundo a autora supracitada, para que se possa incluir os estudantes com NEE, deve-se respeitar e querer desenvolver o indivíduo em todos os aspectos do processo de aprendizagem. Ela escreve que a inclusão no ambiente escolar deve ser necessariamente planejada e estruturada a partir de reflexões pedagógicas.

De acordo com Mantoan, Santos e Figueiredo (2011, p. 6), a inclusão escolar impõe uma escola em que todos os estudantes estejam inseridos sem quaisquer limitações em seu "direito de participar ativamente do processo escolar, segundo suas capacidades, e sem que nenhuma delas possa ser motivo para uma diferenciação que os excluirá das suas turmas".

Desta forma, o estudante com NEE precisa de apoio e ajuda, e não do julgamento dos que o cercam. Isso só reforça suas dificuldades. Para tal, a escola deve ser entendida como "o meio onde a criança retira recursos para atuar através das condutas educativas disponíveis a ele" (ALVES, 2009, p. 39). As interações sociais da família com a escola, da escola com o estudante, e do estudante com os ambientes em que vive são importantes na formação de sua personalidade.

Frente ao exposto, se faz necessário um trabalho conjunto entre a família, profissionais da educação e profissionais da saúde. A participação constante da família ajuda muito no progresso e no tratamento do estudante com NEE/TDAH, bem como na construção de sua cidadania. 
Os estudantes com TDAH incluem-se no grupo dos estudantes com NEE e precisam ser incluídos no ambiente escolar. Porém, devido à invisibilidade de suas deficiências, tal fato não ocorre na abrangência que se necessita. Pessoas com o transtorno costumam apresentar dificuldades para estabelecer relações sociais, resolver problemas, obedecer e compreender regras, compreender ideias abstratas e realizar atividades cotidianas que envolvam o autocontrole.

A inserção do estudante com TDAH na convivência social da escola ocorre por meio da interação e do diálogo entre a família e os profissionais educacionais. No entanto, Alves (2009), avalia que há falta de preparo das escolas e dos educadores para incluir estudantes com necessidades específicas. A ausência de preparo das instituições de ensino pode ser indicada por uma sondagem física da maioria das escolas brasileiras, que não oferecem uma estrutura (física e de recursos humanos) adequada para promover a inclusão desses estudantes.

Para tratar de forma adequada o estudante com TDAH, assim como os demais estudantes com NEE, Alves (2009), afirma que se faz necessária uma equipe multiprofissional composta por profissionais de psicologia, o professor, o terapeuta ocupacional, o fonoaudiólogo, o professor de educação física e o psiquiatra. A ação conjunta desses profissionais contribui com o desenvolvimento de habilidades dos estudantes.

No entanto, Alves (2009, p. 37), observa que: "qualquer profissional tem a condição de realizar alguma coisa para incluir o indivíduo conforme sua capacidade, ritmo e função". Assim, somos compelidos, pelo exercício de nossas funções educacionais, a fornecer subsídios que levem a autonomia do estudante com TDAH.

Segundo as Diretrizes nacionais para educação especial na educação básica, a adoção do conceito de necessidades educacionais especiais e da amplitude da educação inclusiva implica em mudanças significativas. É preciso pensar no estudante e na origem de seu problema e não exigir dele um ajustamento. Cabe ao professor a função de encontrar estratégias que o levem a aprender (BRASIL, 2001). 
Nessa mesma linha de pensamento, Libâneo (1994), defende que ensinar não é só transmitir informações, ensinar implica também a forma de organizar as atividades propostas aos estudantes. Em outras palavras, ensinar vai além de transmitir conteúdos, é valorizar e respeitar o ser humano, é lhe proporcionar o mínimo necessário de instrução para a vivência em sociedade de forma autônoma.

O conceito de autonomia tratado por Paulo Freire cabe nesta discussão, pois se refere a dar condições ao estudante de caminhar sozinho, de pensar, do saber-ser e do saber-fazer, sem conduzir a prática pedagógica como um instrumento para estimular o individualismo e a competitividade (FREIRE, 1996). O saber-ser e saber-fazer são os frutos de uma aprendizagem significativa que inclui todos os estudantes.

Outro aspecto legal que se refere às garantias de acesso à educação escolar dos estudantes com TDAH está presente na Constituição Federal Brasileira, que assegura o ingresso de todos a educação. Igualmente, a Lei de Diretrizes e Bases da Educação Nacional (LDBEN), n 9.394/96 nos artigos 58 e 59, discorre sobre a importância do atendimento educacional a pessoas com necessidades especiais, ministrado preferencialmente em escolas regulares.

A LDBEN apresenta vários elementos que fortalecem a ideia da inclusão, pois, estabelece a criação de serviços de apoio especializado, currículos, métodos, técnicas, recursos educativos e organizações específicas para atender às peculiaridades dos estudantes. Destaca, ainda, a necessidade de capacitar docentes para atender estudantes com dificuldades de aprendizagem.

No que tange os aspectos legais para inclusão, a Constituição Federal veda quaisquer formas de discriminação conforme artigo $3^{\circ}$, inciso IV. Expressa também no artigo 228, inciso III, o dever do Estado em garantir atendimento especializado a pessoas com deficiência (BRASIL, 2019).

Da mesma forma a Resolução n 2 de 2001 do CNE/CEB, que institui as Diretrizes Nacionais para a Educação Especial na Educação Básica, garante o atendimento de estudantes com TDAH, no entanto, não há no momento nenhuma legislação específica sobre esse transtorno e a educação, o que existe, no presente momento, é um 
projeto de Lei do Senado de $n^{\circ} 402$, de 2008, que ainda não foi aprovado (BRASIL, 2001). Garantir direitos a estudantes com transtorno ainda é um desafio a ser vencido.

\section{TDAH E SUAS IMPLICAÇÕES PARA ENSINAR}

Segundo a Cartilha da Inclusão Escolar (ASSOCIAÇÃO BRASILEIRA DE TRANSTORNO DE DÉFICIT DE ATENÇÃO E HIPERATIVIDADE, 2014), as inúmeras tensões no ambiente escolar decorrem das relações que se estabelecem entre o ensino que tende a homogeneização e o choque com os princípios inclusivos, "que supõem o respeito aos direitos, a valorização da diversidade e o atendimento de necessidades individuais." (p. 6).

Nas aulas percebe-se esta dicotomia, entre a homogeneização que ocorre na escola e os princípios inclusivos, além de inúmeros outros desafios pedagógicos. Se tratando da inclusão, os professores das diversas áreas do conhecimento recebem um público com diferentes tipos de NEE e geralmente não estão devidamente preparados e instrumentalizados para atuar nesta nova realidade educacional. Segundo as Diretrizes Nacionais para Educação Especial na Educação Básica:

São considerados professores capacitados para atuar em classes comuns com alunos que apresentam necessidades educacionais especiais, aqueles que comprovem que em sua formação, de nível médio ou superior, foram incluídos conteúdos ou disciplinas sobre educação especial e desenvolvidas competências para: I- receber as necessidades educacionais especiais dos alunos; IIFlexibilizar a ação pedagógica nas diferentes áreas do conhecimento; III- Avaliar continuamente a eficácia do processo educativo; IV-Atuar em equipe, inclusive com professores especializados em educação especial (BRASIL, 2001, p.31-32).

Percebe-se que o processo inclusivo é complexo e exige a adoção de medidas urgentes, sobretudo no que se refere à ação docente. Nesse sentido, Barbosa e Souza (2010), revelam que apesar 
do grande número de pesquisas que têm como foco o professor e dos inúmeros cursos de capacitação oferecidos pelas redes de ensino, pouco tem se revertido em mudanças efetivas das práticas educativas.

Se tratando da disciplina de Ciências da Natureza, as Diretrizes Curriculares Nacionais (DCN) para a Educação Básica (BRASIL 2013), trabalham por meio de eixos de conhecimento e ação e aborda como metodologia de aprendizado a criação de hipóteses e problemas de conhecimento. Os estudos e consequentemente respostas aos questionamentos, são a ligação entre as diversas áreas de conhecimento.

Assim, ocorre a dinâmica dos eixos e os diferentes componentes do currículo apresentam aos estudantes o direito de conhecer e promovem a autonomia de estudar. Para as DCN o currículo escolar não é um conjunto de conteúdos e sim uma plataforma de direitos ao conhecimento, apropriação, pesquisa e expansão (BRASIL, 2013). Frente ao exposto, os professores possuem um papel muito complexo na formação de seus estudantes.

Ainda segundo as DCN é importante adotar estratégias que torne possível, ao longo da Educação Básica, desenvolver o letramento emocional, social e ecológico; o conhecimento científico pertinente aos diferentes tempos, espaços e sentidos; a compreensão do significado das ciências, das letras, das artes, do esporte e do lazer (BRASIL, 2013). Esses elementos apontam para uma educação com a noção de todo e não mais fragmentada pelas diversas disciplinas. Por meio dessa forma de pensar a educação, percebe-se a dimensão do papel do professor como intermediador do processo de inclusão, bem como de mediador do conhecimento.

Um das finalidades da disciplina de Ciências da Natureza é promover o "querer conhecer o mundo", por meio de indagações, dúvidas e questionamentos que surgem a partir de perguntas sobre o próprio ser e do seu ambiente. A disciplina de ciências deve ser trabalhada no sentido de fortalecer a valorização da pluralidade sociocultural, promovendo o conhecimento dos aspectos socioculturais e posicionando-se contra qualquer discriminação baseada em diferenças culturais, de classe social, de crenças, de sexo, de etnia ou outras características individuais e sociais (BRASIL, 1996). 
"Querer conhecer o mundo" é um fator motivador para crianças com TDAH, pois de acordo com Ferreira e outros (2015, p. 157), "é indispensável que o professor motive o estudante, utilizando comportamentos e afetos que sejam sistematicamente orientados para objetivos". O professor deve estimular o entusiasmo e o interesse pela ciência, de modo que os estudantes sintam-se confiantes e competentes para se envolverem com a disciplina, para compreender ideias e conceitos científicos.

De acordo com os autores supracitados, ao professor, cabe a função de possibilitar o aprofundamento de conhecimentos, seja por interesse do próprio estudante, ou por motivação profissional. Nos casos de TDAH, o estímulo e entusiasmo com a disciplina se faz em demasia necessário, visto que os estudantes possuem dificuldades na sustentação da atenção quando algo não lhes faz sentido ou que não Ihes atrai, acarretando problemas no aprendizado.

A falta de motivação do estudante com TDAH é um desafio ao professor que segundo ASSOCIAÇÃO BRASILEIRA DE TRANSTORNO DE DÉFICIT DE ATENÇÃO E HIPERATIVIDADE (2016a, p. 1), "prejudica diretamente duas funções cognitivas essenciais ao desempenho global de qualquer ser humano: atenção e memória". Esse fato torna-se uma barreira para a aprendizagem dos estudantes, pois em alguns casos não encontram "motivos" para estudar (o conteúdo) ou até mesmo a falta de motivação para permanência na escola.

De acordo com o Guia para Professores da Associação Brasileira de Déficit de Atenção (ASSOCIAÇÃO BRASILEIRA DE TRANSTORNO DE DÉFICIT DE ATENÇÃO E HIPERATIVIDADE, 2012, p. 2), é essencial que professores criem "estratégias a serem adotadas em sala de aula para melhorar a capacidade atencional e diminuir os prejuízos decorrentes de comportamentos hiperativos, facilitando, assim, a aprendizagem". Segundo as dicas estabelecidas no guia, é necessário estabelecer rotinas, pois sua inclusão facilita a aprendizagem de todos os estudantes.

As escolas devem proporcionar ao estudante condições ao desenvolvimento da capacidade de aprender, com prazer e gosto. Cada estudante vai requerer diferentes estratégias pedagógicas, que Ihes possibilitem o acesso ao conhecimento socialmente constituído 
e a vida produtiva, condições essenciais para inclusão nas aulas de ciências e o pleno exercício da cidadania. No entanto, não devemos ver estas estratégias como medidas compensadoras e pontuais e sim como parte de um projeto educativo e social de caráter emancipatório e global. (BRASIL, 2001).

Pressupõe-se, que 0 fruto da relação professor/estudantes/conhecimento, nas aulas de ciências, tenha sua base constituída pelo diálogo, em que o professor é o mediador entre as ideias prévias dos estudantes e a visão científica atual. Entretanto, ao mesmo tempo em que as DCN propõem inovação de conteúdos e métodos, reconhecem que poucas destas inovações alcançam a maior parte das salas de aula, onde na realidade, persistem velhas práticas.

Entretanto, Rodrigues (2004), apresenta um estudo de caso, que serve para comprovar a necessidade da reflexão, pois mesmo apresentando sintomas que atrapalhem o processo de aquisição de conhecimento, os estudantes com TDAH são capazes de se alfabetizar linguística e cientificamente.

Entende-se que de acordo com estimativas médicas, publicadas por órgãos da saúde que afirmam que o TDAH é um dos problemas comportamentais mais comuns da infância, que todo professor de ciências já deu ou dará aula a um estudante com esse transtorno, mesmo que isto não seja de seu conhecimento.

\section{PERCURSO METODOLÓGICO}

Segundo Gil (2010), trata-se de uma pesquisa exploratóriadescritiva, pois essa pesquisa tem como objetivo principal verificar se os professores de ciências que atuam nos anos finais do Ensino Fundamental, na cidade de Confresa (MT) conhecem o TDAH e como realizam a prática pedagógica com esses estudantes, ou seja, trata-se do aprimoramento de ideias ou a descoberta de intuições além de propiciar maior familiaridade com o problema tornando-o mais explícito ou construindo hipóteses. Para tal, foi feito levantamento de referências teóricas bibliográficas nas áreas de TDAH, educação inclusiva, ensino de ciências e formação de professores. 
Ainda de acordo com Gil (2010, p. 42), o caráter descritivo em uma pesquisa tem como objetivo "estudar as características de um grupo: sua distribuição por idade, sexo, procedência, nível de escolaridade, estado de saúde física e mental etc". Assim, os aspectos descritivos da pesquisa relacionam as características e padrões de comportamento tidos como recorrentes nos casos de TDAH (grupo classificado segundo padrões de comportamento e de saúde mental).

O estudo procura gerar conhecimentos novos e úteis sem aplicação prática prevista, por isto é um estudo de natureza básica. Apresenta uma abordagem mista, pois segundo Creswell (2007), esse procedimento se desenvolveu em resposta a necessidade de se reunir dados quantitativos e qualitativos em único estudo fazendo proveito dos pontos fortes de cada uma destas metodologias.

Ainda segundo Creswell, os componentes do método misto são: uma lista de perguntas analisadas através de alguma estratégia que busque a abordagem qualitativa. No caso deste estudo a estratégia utilizada foi a descrita pelo autor como triangulação concomitante: "Neste caso, a coleta de dados quantitativos e qualitativos é simultânea, ocorrendo em uma fase do estudo da pesquisa" (2007, p. 219).

Este tipo de análise pode ter o predomínio de uma das técnicas, qualitativa ou quantitativa. Nesse estudo optou-se por dar prioridade à análise qualitativa, pois segundo Gil (2010), busca compreender e interpretar determinados comportamentos dos indivíduos e se propõe a descrever fenômenos referentes a atitudes, representações e padrões, expressos nos formulários respondidos pelos professores investigados da cidade de Confresa.

Os oito participantes do estudo são professores de ciências das escolas Estaduais: Teotônio Carlos da Cunha Neto, Tiradentes e 29 de Julho; da escola municipal Central, e das escolas particulares Milenium e Jaspe, todas localizadas na zona urbana de Confresa, que atuam nos anos finais do Ensino Fundamental ( $8^{\circ}$ e $9^{\circ}$ ano). Todos os participantes foram informados sobre os objetivos da pesquisa os procedimentos e assinaram o Termo de Consentimento Livre Esclarecido (TCLE). Imediatamente receberam o formulário e as orientações de como deveriam proceder com as respostas. 
O instrumento de coleta de dados da pesquisa foi um formulário com oito questões referentes a identificação dos profissionais, três questões gerais sobre o conhecimento que os professores participantes tem acerca do TDAH de modo geral, 19 questões que compreendiam a formação e a atuação destes professores e por último oito questões destinadas aos profissionais que atuam com este público. Dentre os 8 professores participantes da pesquisa, três responderam a última parte do formulário, pois afirmaram trabalhar com estudantes com diagnóstico de TDAH.

Essas questões serviram para identificar se os professores tinham conhecimentos sobre o TDAH e como realizam sua prática pedagógica. Algumas destas questões foram respondidas por meio da escala Likert ${ }^{4}$, que buscou descobrir com que frequência os participantes do estudo concordavam com cada afirmação. Nessa escala foram dispostos cinco opções de resposta: muito frequente, frequente, algumas vezes, raramente e nunca.

Para garantir o anonimato dos participantes da pesquisa, os nomes dos professores foram substituídos por termos alfanuméricos, onde $\mathrm{P}$ é a abreviação de professor e o número que foi dado ao formulário de acordo com a ordem de análise, assim P1 (professor 1), P2 (professor 2), P3 (professor 3) e assim sucessivamente.

Com a finalidade de analisar os dados, primeiramente foi quantificado o número de respostas dadas a cada questão que continha na escala Likert para posteriormente fazer a análise individual de cada formulário, por fim buscou-se comparar os resultados obtidos com a literatura analisada.

\section{RESULTADOS E DISCUSSÃO}

Todos os 8 professores que ministram aulas de ciências nos $8^{\circ}$ e $9^{\circ}$ anos do Ensino Fundamental Regular, da zona urbana de

\footnotetext{
${ }^{4}$ A escala Likert é uma escala psicométrica utilizada em pesquisas quantitativas, já que pretende registrar o nível de concordância ou discordância com uma declaração dada. Onde cada um dos itens é um item likert que recebe pontuação final. Na escala deste estudo buscou-se uma análise da frequência da itens no cotidiano do professor dando Ihe cinco alternativas de resposta: muita frequente, frequentemente, algumas vezes, raramente e nunca (SILVA JUNIOR; COSTA, 2014).
} 
Confresa (MT) participaram da pesquisa. Desses, 5 professores pertencem a da rede estadual de ensino, 1 da rede municipal, 2 da rede particular.

Quando os professores foram indagados se sabiam o que é o TDAH, sete responderam saber e apenas um afirmou desconhecer o problema. Quando questionados se conheciam os possíveis tratamentos, cinco afirmaram conhecer e três disseram desconhecer. Neste ponto podemos notar a contradição de P5 e P6 que ao mesmo tempo em que respondem que sabem o que é o transtorno não possuem conhecimento acerca de seu tratamento.

Ao serem questionados se já tiveram ou se tem estudante(s) com diagnóstico de TDAH, somente três afirmaram que já tiveram, quatro afirmaram que nunca tiveram e $\mathrm{P} 1$ não soube responder. Entretanto, percebe-se uma grande contradição, pois P1, afirmou em outras questões ter tido conhecimento específico em algum momento durante sua formação acadêmica e raramente em sua formação continuada, esse também afirmou saber o que é o transtorno.

Em seu estudo, Rossi e Rodrigues (2009, p. 215), constataram que os professores do Ensino Fundamental, participantes de sua pesquisa, no geral, pouco sabem diferenciar os sintomas presentes em estudantes com TDAH. Percebe-se que esta também é a realidade encontrada junto aos professores de ciências de Confresa. As autoras supracitadas analisaram as definições de TDAH feitas por um conjunto de professores (39), onde observaram que as definições destes geralmente se referem aos excessos comportamentais.

Ainda segundo Rossi e Rodrigues, o TDAH permanece mal compreendido e problemático nas informações dadas ao público em geral e das prestadas as autoridades educacionais. Afirmam elas que para o professor a dificuldade começa na identificação e encaminhamento adequado destes estudantes, "principalmente porque o transtorno não está descrito de maneira objetiva quanto à sua delimitação e ao uso de critérios para se fazer o diagnóstico" (ROSSI; RODRIGUES, 2009, p. 2016).

Para reafirmar o conhecimento insipiente dos professores com a temática, notamos que ao confrontar os questionamentos referentes se sabiam o que é TDAH e se teve ou tem estudante(s) com 
diagnóstico, a metade dos professores (4) afirma não ministrar aulas a estudantes com diagnóstico de TDAH. No entanto, quatro destes professores são atuantes em escolas públicas, possuindo uma média superior a 30 estudantes por sala e atuam em diversas turmas, o que demonstra o desconhecimento dos professores, pois de acordo com as estatísticas médicas, no mínimo, 1 a cada 40 estudantes apresenta o transtorno. Percebe-se também a falta de preparo das escolas e seus profissionais para indicar avaliação médica para a família.

Outro fato que chamou atenção diz respeito ao P1, que não soube informar se teria estudantes com o transtorno. Entretanto, no setor de registro escolar, constatamos haver duas estudantes com diagnóstico nas turmas em que esse mesmo professor atua. Esta constatação serve de alerta a ausência de diálogo entre a escola e o professor e da falta de preparo de ambos para lidar com estudantes com NEE, em especial o TDAH. Percebe-se que não há uma boa integração entre escola/professor/família, que é essencial para o aprendizado de qualquer estudante.

Entretanto Silvestre e outros (2015), afirmam que é possível obter resultados satisfatórios na trajetória escolar da criança com TDAH quando se têm professores e coordenadores comprometidos e envolvidos em pensar intervenções estratégicas e sobretudo a colocá-las em prática. Nesses casos, é preciso que os professores auto avaliem sua prática pedagógica, considerando as especificidades de cada estudante.

Comungando da mesma linha de pensamento é importante acrescentar que o diálogo entre família e escola vem a contribuir significativamente com o aprendizado do estudante, pois, "Através da integração das instituições família e escola, amparadas por especialistas na área da saúde, a criança com TDAH terá um percurso de conquistas e vitórias em seu desenvolvimento escolar" (SILVESTRE et al, 2015, p. 13).

Constatamos que os professores de ciências que atuam na cidade de Confresa, não conhecem o quanto práticas pedagógicas rotineiras podem contribuir significativamente com o aprendizado ou favorecer a concentração de qualquer estudante. Participaram do estudo professores que possuem tempo de magistério variando de entre quatro meses a 32 anos de profissão. Neste caso, o tempo de 
experiência não significou mais conhecimento sobre a temática, pelo contrário, o professor com maior tempo de magistério (P6), se contradisse em seu formulário, ora mencionava conhecer o transtorno, ora afirmava nunca ter tido formação acadêmica e continuada a respeito do TDAH e também não conhecer os tratamentos possíveis.

Quando questionados se estabeleciam uma rotina mantendo a sala organizada e estruturada, a maioria (5) dos professores afirma estabelecer rotinas frequentemente em sala de aula. Afirmam ainda, criar regras claras e objetivas com frequência que ajudam na manutenção da disciplina. Nesse sentido, a Associação Brasileira de Transtorno de Déficit de Atenção e Hiperatividade - ABDA (2012) alega ser necessário que os professores estabeleçam uma rotina diária no sentido de promover/facilitar a aprendizagem de estudantes com TDAH. Nesse caso, verifica-se que os professores atendem a estratégia divulgada pela ABDA que pode contribuir com a atenção de estudantes.

Quando questionados se em sua prática pedagógica traziam elementos do cotidiano dos estudantes, metade afirmou que trazia com frequência e a outra metade o faz com muita frequência. O Guia para professores da ABDA (2012), sugere que o professor contextualize a aula com o cotidiano dos estudantes, isso contribui para atrair o interesse do estudante, estimulando-o e motivando-o para o aprendizado. Percebe-se que os professores de ciências investigados possuem a compreensão da importância da contextualização do conteúdo a ser ensinado visando promover a motivação para que o processo de ensino e aprendizagem aconteça de forma mais interessante.

Os resultados supracitados, também indicam que o comportamento do professor em sala de aula influência na atenção do estudante com TDAH. Segundo o Guia citado, o professor que se movimenta em sala chama mais a atenção. Da mesma forma, professores motivadores, engraçados e que chamam os estudantes pelos nomes, que oscilam a entonação e o volume da voz obtém mais sucesso no trato com este público.

Porém, quatro professores afirmaram ser dinâmicos frequentemente, dois afirmaram que muito frequentemente e dois 
afirmaram que algumas vezes são dinâmicos. Seis dos participantes afirmam que tem o hábito de movimentar-se muito frequentemente em sala de aula. Metade dos investigados (4), afirma oscilar a entonação de voz algumas vezes e outra metade com frequência. Esses resultados indicam que a maioria dos professores (talvez sem conhecimento), realiza sua prática docente em conformidade com as orientações apresentadas no guia.

Ao avaliar suas aulas os professores de ciências, em sua maioria, as consideram frequentemente motivadoras. No entanto P3 e P6 consideram que suas aulas, algumas vezes, são motivadoras. A ABDA em texto acerca da importância da motivação, diz que a falta desta, acaba por consequência afetando o desempenho escolar do estudante com TDAH, pois se não há motivação, não se sustenta a atenção, e se não há atenção sustentada, não há memória e não se aprende (ABDA, 2016a). Nesse sentido, o uso de estratégias de ensino que encoraje a participação do estudante pode ser considerado um ponto de partida para motivá-los, mas ao escolher a estratégia o professor deve analisar as formas de pensar e aprender dos estudantes com TDAH.

Perguntamos se o professor motiva seu estudante com TDAH a participar da aula. Daqueles que afirmaram possuir estudantes com o transtorno, todos afirmam que frequentemente estimulam a participação. Em seu estudo Tubbs (2013), descreve sobre a importância dos estudantes com TDAH estarem constantemente motivados para que possam ser capazes de se concentrar. Assim, verifica-se que todos os professores investigados ao proporcionar a participação do estudante, estão contribuindo com o desenvolvimento de sua autonomia e essa forma de motivação pode levar a uma nova aprendizagem, assim como a aprendizagem levar a novas motivações.

Os três professores, que afirmaram possuir estudantes com TDAH, alegam estimular e elogiar seus estudantes quando aprendem o conteúdo; porém percebe-se que há uma divergência quando somente dois trabalham com frequência as recompensas, tais como: deixar que este estudante seja o ajudante do professor, Ihe conceder a vez para apagar o quadro, ou ir buscar algo fora de sala, ou mesmo 
elogios verbais e escritos. E o professor P4, afirma que só trabalha algumas vezes com estes estímulos.

Segundo ABDA (2012), é comum a baixa autoestima em pessoas com TDAH, pois recebem críticas constantemente e podem refletir em sua vida estudantil. Elogiar, estimular seu esforço é um modo de valorizá-lo e de instigar sua autoestima com grandes chances de observar um crescimento intelectual.

Outra atitude positiva frequentemente usada pelos professores é colocar os estudantes com TDAH nas primeiras carteiras. Observou-se na resposta dos professores que afirmam ter estudantes com o transtorno, que um professor coloca os estudantes, muito frequentemente, nas primeiras carteiras e dois adotam essa medida com frequência.

Essa prática corrobora a afirmativa presente na cartilha da ABDA (2012), no qual colocar os estudantes com o transtorno nas primeiras carteiras facilita que o professor o ajude e o monitore, pois, o professor terá mais controle do seu comportamento desatento ou hiperativo sentando-o na frente na sala de aula, próximo ao quadro. Isso permite o contato mais direto entre o professor e estudante, visto que essa ação se faz necessária devido às condições da tríade sintomática (hiperatividade, impulsividade e déficit de atenção) do transtorno que ocasiona déficits de aprendizagem.

Geralmente, os estudantes com TDAH apresentam dificuldade para se organizar e planejar os estudos. Portanto, o professor deve estabelecer técnicas de organização para favorecer o estudo em casa. A criação de uma agenda escola-casa possibilita a organização de atividades e trabalhos para serem realizados em casa, é um importante veículo de informações, facilita a comunicação entre o professor e os pais. Pode conter informações sobre o comportamento em sala de aula e necessidade de estudos para determinado conteúdo. Enfim, pais e professores poderão manter um canal de comunicação para saber como está o estudante.

No entanto, dentre os três professores que tem estudantes com TDAH, e respondeu o formulário específico, P4 afirmou que raramente ensina técnicas de organização a seus estudantes. P4 também havia afirmado que em sua formação acadêmica e continuada frequentemente recebia informações sobre o transtorno, 
mas afirmou também que raramente mantém a comunicação com os pais. O que demostra que o processo de inclusão desses estudantes ainda é considerado um grande desafio para a educação brasileira, pois os professores em seus cursos de formação inicial e continuada deveriam ser melhor preparados para lidar com as diferentes necessidades de aprendizagem dos estudantes.

Nas questões referentes à formação acadêmica e continuada do professor de ciências, a maioria (7) afirmou que procura ler com frequência a respeito dos transtornos comportamentais, afirmam ainda ter tido conhecimento a respeito do TDAH. Mas, em contra partida afirmam que em sua formação continuada poucos são os conhecimentos obtidos a respeito do transtorno.

O caso de P6 chama a atenção, pois afirma nunca ter tido conhecimento acadêmico ou de formação continuada a respeito do TDAH, mesmo sendo um profissional bastante experiente. Afirmou ainda que raramente busca conhecimento a respeito do transtorno. Segundo Amaral (2013, p. 2), se faz

[...] necessária uma formação adequada destes profissionais e comprometimento para conseguirem atender a esta demanda e, ainda mais os estudantes que apresentam este transtorno específico, exigindo do professor um trabalho diferenciado.

De acordo com a pesquisa realizada pelo autor, todos os professores entrevistados por ele, concordam que a formação do professor não é suficiente para atender a inclusão de estudantes com TDAH. Isso reafirma o fato de que os professores precisam de formação adequada que contemple os temas TDAH, inclusão escolar, entre outros.

A princípio, a escolha de professores de ciências das séries finais do Ensino Fundamental baseou-se na tentativa de encontrar maior quantidade de professores formados na área atuando na cidade de Confresa. Entretanto, constatamos que mais da metade (5) dos professores atuantes são formados em áreas afins como a Biologia (4) e Química (1). 
Esse fato também é apresentado nos estudos de Magalhães Júnior e Pietrocola (2011, p. 175-176), que afirmam que a maioria dos professores que ministram a disciplina de ciências

[...] é egressa de cursos de licenciatura em Biologia, que focam a formação em conteúdos de biologia, não proporcionando uma formação sólida nas outras áreas das ciências, necessárias para o bom desenvolvimento da disciplina de ciências.

Percebe-se, que assim como em outras cidades brasileiras, em Confresa, a maioria dos profissionais que ministram aulas de ciências é egressa dos cursos de licenciatura em Biologia. Esse estudo também comprovou que há profissionais que ministram esta disciplina e possuem outras áreas de formação, tais como: Letras e Pedagogia, o que demonstra um déficit de profissionais da área.

Os conteúdos de ciências, em especial aqueles que abordam saúde e corpo humano são uma possibilidade de se trabalhar os transtornos psiquiátricos e o TDAH, a fim de desmistificar e quebrar preconceitos acerca dos transtornos mentais. Daí a importância de se ter um professor devidamente capacitado, pois poderá propor uma investigação sobre os diferentes tipos de transtornos. Segundo Araújo (2012), é necessário se pensar em como lidar com a diversidade, criar melhores relações no âmbito escolar, propiciar um ambiente escolar adequado e refletir sobre as maneiras de se superar as dificuldades de aprendizagem para assim aumentar a aprendizagem do estudante e a qualidade de ensino.

Devido às estimativas médicas de incidência, todo professor já ministrou ou ministrará aula a um estudante com TDAH. Para validar esta consideração, os professores responderam a questão referente ao número médio de estudantes por sala, e ainda, se já haviam ministrado aula para estudantes com o transtorno. Os resultados apresentam que a média dos estudantes por sala variou entre 12 a 33, as menores médias são de escolas particulares e as maiores de escolas públicas.

Nesse sentido, Marques, Pelicioni e Pereira (2007, p. 14) acrescentam que "a superlotação das salas de aula da escola pública de Ensino Fundamental - uma das principais diferenças em relação à 
escola particular - agrava consideravelmente a má qualidade do ensino, contribuindo para o descumprimento da sua função". No Brasil esse ainda é considerado um problema recorrente, visto que, não muitas vezes, não se cumpre o limite máximo estabelecido em legislação.

O grande número de estudantes nas escolas públicas, em média 30 por sala, pode dificultar o trabalho do professor, a aprendizagem dos estudantes, a metodologia aplicada em sala e principalmente a atenção e atendimento individual aos estudantes com TDAH (MARIANO; MUNIZ, 2006).

Após a análise dos dados, foi possível verificar que os professores de ciências demonstraram possuir conhecimento insipiente acerca do TDAH. O conhecimento que possuem não é suficiente para terem certeza que estão lidando com um estudante com TDAH ou para questionarem a respeito da saúde mental destes e por conseguinte, poder contribuir para seu processo de tratamento e aprendizagem.

\section{CONSIDERAÇÕES FINAIS}

Considerando que o objetivo dessa pesquisa foi investigar o que os professores de ciências de Confresa conhecem sobre a temática TDAH e suas práticas junto a estudantes com o transtorno, uma primeira constatação foi que os professores de ciências demonstraram possuir conhecimento insipiente acerca do Transtorno. Dentre os entrevistados, menos da metade afirmaram possuir estudantes com o transtorno e dentre esses, três professores observou-se o desconhecimento quanto às técnicas necessárias para a inclusão e melhoramento da aprendizagem desses estudantes. Verificou-se que professores que atuam em sala de aula, local onde os sintomas aparecem com clareza, não identificam a percepção dos sintomas de TDAH.

Entretanto, ainda hoje, a ausência de percepção dos sintomas do transtorno, pelos professores de ciências esbarra na falta de conhecimento, mesmo que os sintomas apareçam com frequência, esses profissionais não o identificam. Se esses profissionais fossem 
devidamente capacitados e informados, poderiam sugerir uma investigação de diagnóstico para alguns de seus estudantes.

Foi possível verificar que o processo de inclusão do estudante com TDAH necessita da mobilização dos âmbitos político, social e institucional, bem como da capacitação dos profissionais da educação. Entretanto, cabe destacar que a questão da inclusão não pode ser tomada como responsabilidade unicamente do professor, mas a ele cabe uma parcela relevante do processo, bem como o encaminhamento do estudante para avaliação de diagnóstico e tratamento.

Constou-se que os professores de ciências pesquisados não tem conhecimento sobre como as práticas pedagógicas rotineiras podem contribuir significativamente com o aprendizado ou favorecer a concentração de estudantes com TDAH. A maneira como os cursos de formação acadêmica e continuada são propostos, favorece a perpetuação da falta de informação/formação a esse respeito.

Quanto à tríade de diálogo entre escola/família/professor, o estudo demonstrou que essa é uma grande fragilidade nas escolas da zona urbana do município de Confresa (MT), pois a direção se exime do papel educacional, deixa os professores como principais responsáveis do problema, o que não são. As famílias também se omitem da responsabilidade deixando a educação de seus filhos nas mãos da escola. E nessa situação predomina a falta de informação e o grande prejudicado é o estudante com o transtorno.

Porém, a escola precisa criar mecanismos para que a família acompanhe a vida escolar dos filhos e esteja mais próxima da escola na formação destes cidadãos. Nesse contexto, o professor assume papel relevante, pois a ele compete à função de ensinar o estudante com TDAH. Logo, para que esse processo ocorra, o professor deve entender que é o TDAH, como se trata e quais consequências na vida dos estudantes.

\section{REFERÊNCIAS}

ALVES, Fátima. Inclusão: muitos olhares, vários caminhos e muitos desafios. 2. ed. Rio de Janeiro: Editora Wak, 2009. 
AMARAL, Alice B. et al. A formação do professor para trabalhar com crianças que apresentam diagnóstico de TDAH no ensino fundamental I na rede municipal de ensino de Curitiba. Ensaios Pedagócicos, Revista Eletrônica do Curso de Pedagogia das Faculdades OPET. dez.2013 Disponível em: http://www.opet.com.br/faculdade/revistapedagogia/pdf/n6/ARTIGO-MONICA.pdf. Acesso em: 20 jul. 2016.

ARAÚJO, Marcos V. Manejo comportamental do professor do contexto de sala de aula de aluno identificados com TDAH: desenvolvimento e implementação e avaliação de guia de intervenção. 2012. Tese (Doutorado em Distúrbio do Desenvolvimento) - Universidade Presbiteriana Mackenzie. São Paulo, 2012. Disponível em: http://tede.mackenzie.br/jspui/handle/tede/1761. Acesso: 20 jul. 2016.

ASSOCIAÇÃO BRASILEIRA DE TRANSTORNO DE DÉFICIT DE ATENÇÃO E HIPERATIVIDADE. Motivação é coisa séria. $15 \mathrm{abr}$. 2016a . Disponível em: https://tdah.org.br/motivacao-e-coisa-seria/. Acesso: 2 jul. 2017.

ASSOCIAÇÃO BRASILEIRA DE TRANSTORNO DE DÉFICIT DE ATENÇÃO E HIPERATIVIDADE. Cartilha da Inclusão escolar: Inclusão baseada em Evidências Cientificas. [2014]. Disponível em: https://tdah.org.br/cartilhas-da-abda/. Acesso: 2 jun. 2017.

ASSOCIAÇÃO BRASILEIRA DE TRANSTORNO DE DÉFICIT DE ATENÇÃO E HIPERATIVIDADE. Direito dos portadores de TDAH:

Doutrina - Jurisprudência. [2016b]. https://www.tdah.org.br/wpcontent/uploads/site/pdf/cartilha_legislacao.final.pdf. Acesso: 2 jun. 2017.

ASSOCIAÇÃO BRASILEIRA DE TRANSTORNO DE DÉFICIT DE ATENÇÃO E HIPERATIVIDADE. TDAH e o processo de aprendizagem. 8 jun. 2016c. Disponível em: https://tdah.org.br/tdah-e-o-processo-de-aprendizagem/. Acesso: 20 jul. 2016. 
ASSOCIAÇÃO BRASILEIRA DE TRANSTORNO DE DÉFICIT DE ATENÇÃO E HIPERATIVIDADE. O que é o TDAH. [2016d].

Disponível em: https://tdah.org.br/sobre-tdah/o-que-e-tdah/. Acesso: 2 dez. 2016.

ASSOCIAÇÃO BRASILEIRA DE TRANSTORNO DE DÉFICIT DE ATENÇÃO E HIPERATIVIDADE. TDAH - Guia para Professores.

2012. Disponível em: https://tdah.org.br/tdah-guia-paraprofessores/. Acesso: 2 jul. 2017.

BARBOSA, Eveline Tonelotto; SOUZA, Vera Lucia Trevisan. A vivência de professores sobre o processo de inclusão: um estudo da perspectiva da Psicologia Histórico-Cultural. Revista

Psicopedagogia. v. 27 n. 84. São Paulo. 2010. Disponível em: http://pepsic.bvsalud.org/scielo.php?script=sci_arttext\&pid=S010384862010000300005. Acesso em: 20 jul. 2016

BELTRAME, Thaís S.; SILVA, Juliana; SAVISKI, Gilmar.

Desenvolvimento psicomotor e desempenho acadêmico de escolares com idade 10 e 12 anos, com indicativo de transtorno da falta de atenção/hiperatividade. Cinergis, v. 8, n. 1, p. 33-39, jan./jun, 2007. Disponível em:

https://online.unisc.br/seer/index.php/cinergis/article/view/545. Acesso em: 21 jul. 2017.

BRASIL. Constituição da República Federativa do Brasil. Brasília: Supremo Tribunal Federal, Secretaria de Documentação, 2019. Disponível em:

http://www.stf.jus.br/arquivo/cms/legislacaoConstituicao/anexo/CF. pdf. Acesso em: 05 jan. 2017.

BRASIL. Lei n 9.394, de 20 de dezembro de 1996. Estabelece as diretrizes e bases da educação nacional. Diário Oficial da União, Brasília, DF, 23 dez. 1996. Disponível em:

http://www.planalto.gov.br/ccivil_03/leis/L9394.htm. Acesso em: 17 abr. 2013.

BRASIL. Ministério da Educação. Secretaria de Educação Básica.

Diretrizes nacionais para a educação básica. Brasília: MEC, SEB, DICEl, 2013. Disponível em: http://portal.mec.gov.br/docman/julho- 
2013-pdf/13677-diretrizes-educacao-basica-2013-pdf/file. Acesso em: 20 set. 2017.

BRASIL. Mistério da educação. Diretrizes nacionais para a educação especial na educação Básica. Secretaria de educação especial. MEC; SEESP, 2001. Disponível em:

http://portal.mec.gov.br/seesp/arquivos/pdf/diretrizes.pdf. Acesso em: 10 set. 2017

CRESWELL, John W. Projeto de pesquisa: Metodos qualitativo, quantitativo e misto. 2. ed. Porto Alegre: Artmed. 2007. Disponível em:

https://edisciplinas.usp.br/pluginfile.php/696271/mod_resource/con tent/1/Creswell.pdf. Acesso em: 17 abr. 2016.

FERNANDES, Tereza Liduina Grigório; VIANA, Tânia Vicente. Alunos com necessidades educacionais especiais (NEEs): avaliar para o desenvolvimento pleno de suas capacidades. Est. Aval. Educ., São Paulo, v. 20, n. 43, maio/ago. 2009. Disponível em:

http://www.fcc.org.br/pesquisa/publicacoes/eae/arquivos/1495/149 5.pdf. Acesso em: 20 ago. 2016

FERREIRA, Maria Eduarda et al. Literacia Científica e Inclusão Através da Educação em Ciências: caso de uma criança portadora de TDAH. Revista Electrónica de Investigación y Docencia (REID), p. 153168, 13 jan. 2015. Disponível em:

http://revistaselectronicas.ujaen.es/index.php/reid/article/viewFile/1 397/1945. Acesso em: 20 ago. 2016

FREIRE, Paulo. Pedagogia da autonomia: saberes necessários à prática educativa. 25. ed. São Paulo: Editora Paz e Terra, 1996.

GIL, Antônio Carlos. Como elaborar projetos de pesquisa. 5. ed. São Paulo: Editora Atlas, 2010.

LIBÂNEO, José Carlos. Processo de ensino na escola. In: LIBÂNEO, José Carlos. Didática. São Paulo: Cortez, 1994.

MAGALHAES JUNIOR, Carlos Alberto de Oliveira; PIETROCOLA, Mauricio. Atuação de professores Formados em Licenciatura Plena em Ciências. Alexandria Revista de Educação em Ciências e Tecnologia. Santa Catarina, v. 4 n.1. 2011. Disponível em: 
https://periodicos.ufsc.br/index.php/alexandria/article/view/37553. Acesso: 10 jul. 2016.

MANTOAN, Maria Teresa Eglér; SANTOS, Maria Terezinha da Consolação Teixeira dos. FIGUEIREDO, Rita Vieira de. Fascículo da Educação Especial. Ministério da Educação e Cultura - MEC, Brasília, 2011.

MARIANO, Maria do Socorro Sales; MUNIZ, Hélder Pordeus.

Trabalho docente e saúde: o caso dos professores da segunda fase do ensino fundamental. Estudos e pesquisas em psicologia. Rio de Janeiro, v. 6, n.1. 2006. Disponível em:

http://www.revispsi.uerj.br/v6n1/artigos/PDF/v6n1a07.pdf. Acesso: 20 ago. 2016

MARQUES, Elias P; PELICIONI, Maria C. F.; PEREIRA, Isabel M T B. Educação pública: falta de prioridade do poder público ou desinteresse da sociedade? Rev Bras Crescimento Desenvol Hum. São Paulo, v.17, n. 3. 2007. Disponível em:

http://pepsic.bvsalud.org/scielo.php?script=sci_arttext\&pid=S010412822007000300003. Acesso: 20 ago. 2016

RODRIGUES, Ana Lucia M. A criança com TDAH tem capacidade de Aprender? Rio de janeiro, 2004. Disponível em:

http://www.avm.edu.br/monopdf/6/ana\%20lucia\%20mariz\%20rodri gues.pdf. Acesso: 22 ago. 2017.

ROSSI, Liene Regina; RODRIGUES, Olga Maria P. R. Concepções dos professores do ensino fundamental sobre TDAH. In: VALLE, TGM., org. Aprendizagem e Desenvolvimento humano: avaliações e intervenções [online]. São Paulo: Cultura Acadêmica, 2009.

Disponível em: http://books.scielo.org/id/krj5p/pdf/valle9788598605999-11.pdf Acesso: 22 ago. 2017.

SILVA JUNIOR, Severino Domingos da Silva; COSTA, Francisco José. Mensuração e Escalas de Verificação: uma Análise Comparativa das Escalas de Likert e Phrase Completion. Revista Brasileira de

Pesquisas de Marketing, Opinião e Mídia, São Paulo, v. 15, p. 116, out. 2014. Disponível em:

http://www.revistapmkt.com.br/Portals/9/Volumes/15/1_Mensura\% 
C3\%A7\%C3\%A30\%20e\%20Escalas\%20de\%20Verifica\%C3\%A7\%C3\% A3o\%20uma\%20An\%C3\%A1lise\%20Comparativa\%20das\%20Escalas \%20de\%20Likert\%20e\%20Phrase\%20Completion.pdf. Acesso em: 15 dez. 2016.

SILVA, Ana Beatriz B. Mentes inquietas: TDAH: desatenção, hiperatividade e impulsividade. 2.ed. Rio de Janeiro: Objetiva, 2010. Disponível em: http://lelivros.com/book/download-mentesinquietas-ana-beatriz-barbosa-silva-em-epub-mobi-e-pdf/. Acesso: 12 set. 2016.

SILVA, Dalila Helena; DUTRA, Mara Maria. Transtorno de déficit de atenção e hiperatividade: como os professores de ciências de Confresa-MT estão lidando com o assunto? MOSTRA DE TRABALHOS DOS CURSOS DE ESPECIALIZAÇÃO DO IFMT CAMPUS CONFRESA, 1., 2016, Confresa-MT. Anais eletrônicos [...]. Confresa-MT: IFMT, 2016, p. 81-85. Disponível em: https://drive.google.com/file/d/OB6TeUgVsQcJATkhWME9IdWRyZU U/view. Acesso em: 20 dez. 2016.

SILVESTRE, Áurea et al. Família e a escola na aprendizagem da criança com TDAH: a necessidade de uma parceria ativa e produtiva. Pedagogia em ação. v.7, . 1, 2015. Disponível em:

http://periodicos.pucminas.br/index.php/pedagogiacao/article/view/ 11042. Acesso em: 17 set. 2017.

TUBBS, Silvana Silveira da C. O papel da coordenação escolar na orientação de professores no trabalho com alunos portadores de TDAH nas séries iniciais. 2013. Disponível em: https://www.unovacursos.com.br/online/aluno/trabalhos/143491259 212.doc. Acesso: 05 ago. 2017.

Recebido em: Janeiro/ 2020.

Aprovado em: Dezembro/ 2020. 